\title{
Engine performance testing using variable RON95 fuel brands available in Malaysia
}

\author{
Aizuddin Fahmi Mohd Riduan ${ }^{1, *}$, Noreffendy Tamaldin ${ }^{1,2}$, and Ahmad Kamal Mat Yamin ${ }^{1,2}$ \\ ${ }^{1}$ Faculty of Mechanical Engineering, Universiti Teknikal Malaysia Melaka, Hang Tuah Jaya, 76100 \\ Durian Tunggal, Melaka, Malaysia. \\ ${ }^{2}$ Centre for Advanced Research on Energy, Universiti Teknikal Malaysia Melaka, Hang Tuah Jaya, \\ 76100 Durian Tunggal, Melaka, Malaysia.
}

\begin{abstract}
There are various gasoline fuel producers available in Malaysia. The effects of fuel variations from different manufacturers on vehicle performance have always been a debate among users and currently the facts still remains inconclusive. Hence, this study focuses on analyzing various RON95 fuel brands available in the Malaysian market and finding the differences towards engine performance. In terms of engine output, the important data of power (hp) and torque (Nm) will be gathered by using an engine dynamometer. Another data that would also be taken into account is the knocking where the relative knock index can be measured in percentage using the knock sensor accelerometer. Results have shown that the performance of different fuel brands tested are indeed different albeit by only a small margin even though all fuels are categorized with the same octane rating. The power and torque results also imply that both are influenced by the amount of vibration generated due to engine knocking. Based from the overall outcome, consumers would not need to only focus on a certain type of gasoline brand as all differentiates the engine performance marginally.
\end{abstract}

\section{Introduction}

In Malaysia, most all of the fuel brands that sell gasoline would offer octane ratings of RON95 and RON97. Various gasoline fuel brands with different octane ratings are sold at a fixed price which is regulated by a managed float system that was implemented on $1^{\text {st }}$ of December 2014 to cut out all the fuel subsidies. As of $1^{\text {st }}$ April of 2016, the fuel prices for both RON95 and RON97 were set at RM1.70/L and RM2.05/L respectively. The most common query among users about the difference in fuel brands is whether or not all of them are the same or unlike when used in their vehicles even though the gasoline used has the same octane rating and price point. Hence, this research examines certain RON95 fuel brands available in Malaysia and discuss the differences between all tested gasolines.

Gasoline is a type of chemical mixture that consists of numerous hydrocarbons. It varies from one refinery to another and there no ideal reference point that can be used to portray the quality and purity of gasoline as a whole [1]. In this study, octane rating defines the

\footnotetext{
${ }^{*}$ Corresponding author: lucky_din_v1@yahoo.com
} 
characteristics of the gasoline. Octane rating can be determined by three methods which are Research Octane Number (RON), Motor Octane Number (MON), and Anti-Knock Index (AKI). The difference between all octane ratings does not necessarily mean the fuel would have difference fuel performance when tested on. It is just simply a method of measurement that can be categorized through a standard experiment procedure.

RON is measured by testing fuel in an engine that has a variable compression ratio under controlled conditions. MON in the other hand is a step up test from RON where the fuel will be tested with a higher engine speed, preheated fuel mixture, and also with a variable ignition timing to increase knock resistance load of the fuel. Both of those octane ratings are still measured in a standardized single cylinder, variable compression ratio (from 4:1 to 18:1), internal combustion engine (Cooperative Research Fuel-CFR engine), according to the standard methods ASTMD2699 and D2700, respectively [1 -2$]$. The engine is kept at a constant operating speed, where $600 \mathrm{rpm}$ for RON and $900 \mathrm{rpm}$ for MON, and the compression ratio is increased until the onset of knocking. [1]. The RON accounts for fuel performance under low severity engine operation while the MON for more severe operation that might be incurred at high speed or high load [1]. Anti-Knock Index meanwhile is just a formula of $(\mathrm{RON}+\mathrm{MON}) / 2$ where is sometimes can also be known as Pump Octane Number (PON) and Road Octane Number (RdON). The difference between all of the types of measurement is the fuel sensitivity towards the experiment however the similarity between all is that all the results were compared to a standard mixture of iso-octane and n-heptane. As an example a fuel with an octane rating of 95 means it is similar to a standard fuel of $95 \%$ iso-octane and $5 \%$ heptane. Octane quality for a fuel is essential to avoid knocking phenomena. The absence of knocking will able combustion phasing of a spark ignition (SI) engine to be tuned optimally. It allows engine to work on high-load operating points more efficiently. Furthermore, engine compression ratio $(\mathrm{CR})$ can also be increased which in return improves the whole range of engine speed and load thermodynamic efficiency [3].

Typically, it is conceived that a higher octane number increases engine performance. This thought has attracted the general public to use gasoline of a higher octane for their vehicles [4]. Adding oxygenates such as tetra-ethyl lead (TEL), methyl tertiary butyl ether (MTBE), or tert-amyl methyl ether (TAME) to fuels can increase efficiency of combustion and ignition, stabilizing fuel mixture, preserve the motor from erosion, as well as reducing harmful emissions. Adding nanomaterials into the liquid fuel as catalyst will accelerate the burning rate and promote clean burning. As an example, cerium oxide (CeO2) nanoparticles was tested as a gasoline additive to improve combustion [5]. One other research suggests that addition of alcohol to gasoline such as butanol can help reduce the knocking effect of the engine [6]. Another study that also tempered with the gasoline blend was done by David A. Rothamer and Jamie H. Jennings where they mixed the fuel with 2 , 5-Dimethylfuran and ethanol to test the knocking propensity [7]. More examples can be seen where a research conducted an experiment of testing different fuel octane numbers, where the differences of the fuel can be characterized by different content of olefins and oxygen [8]. Based on the studies reviewed, it is shown that adding additives can play a major part in contributing towards engine efficiency which would explain different fuel brands of the same octane rating can variably affect engine performance.

To determine the difference between tested fuels, another quantity that will be look upon is the knocking of an engine. Knocking has been a pivotal problem for fuel efficient and high compression ratio SI engines development for more than 60 years [10]. Knocking phenomena takes place when end gas auto-ignition is ahead of the propagating flame. When auto-ignition happens in the combustion chamber, the chemical energy contained in the end gas is released rapidly. At a certain magnitude, shock waves propagation occurs across the cylinder causing it to resonate at its natural frequencies. This will result to high 
frequency shock waves striking the cylinder walls and inducing permanent damage [9]. These pressure waves are carried through the engine structure to the surrounding air leading to the combustion 'ping' sound be heard in close range. [11]. Pressure waves resulted from knocking happens at frequencies that are acoustic vibration modes of the chamber geometry. Amplitude of the oscillations linked immediately with each resonant mode after the occurrence of knock depending on the initial boundary conditions. The oscillations frequencies depend on the shape and size of the chamber, auto-ignition location, resonant mode, and the sound average speed. Vibration modes can be radial and circumferential, and the range of frequencies are between $6-25 \mathrm{kHz}$ for automotive sized engines [11]. Whatever reasons that might lead to knocking, normally it is tripped by rapid combustion and release of unequally distributed energy in the combustion chamber [12].

Modern SI engines requirement nowadays are directed towards low fuel consumption and reduced pollutant emissions. A simple approach in obtaining better thermal efficiencies for SI engines is increasing the CR. At part load, higher thermal efficiency can be achieved by raising the $\mathrm{CR}$ or by means of supercharging (concept of downsizing) $[13,16]$. In the last decade, small sized SI engines working under high loads have become more favourable for car manufacturers. The big advantage of such engines is the increase in efficiency and reduction of $\mathrm{CO}_{2}$ emissions [14]. Nevertheless, for every great improvement of engines thermal efficiency, one major challenge faced from SI engine is the underlying problem of combustion knock [15]. A higher compression ratio contributes to greater unburned end gas pressure and temperatures, which develops a spontaneous ignition from the portion of unburned end gas mixture. Still, this end gas auto-ignition also produces high-frequency oscillations and shockwaves and of the in-cylinder pressure, which consequently cause engine knocking [16]. Hence, it has been a key technical obstruction for modern SI engines to increase power per litre extensively while limited to knock [15].

According to one research [18], these can be the consequences of prolong effect by knocking:

- Piston rings breakage

- Cylinder head, piston crown, and top land erosion

- Melting of piston

- Limiting engine CR or acceleration performance of vehicle

- Greater air pollution

- Lower engine efficiency

- Increase in fuel consumption

- Structural damage to engine in the long run

- Source of intolerable noise

Prediction of knocking is very difficult and requires specific information of the occurring process within the combustion chamber. In SI engines, the combustion phenomenon can be proceed as normal or unnatural depending on engine operating conditions [17]. Detection of knock are commonly obtained from data gathered by either cylinder pressure sensors or accelerometers. Because of its simplicity, vibration measurement using accelerometer is widely used in industry. Even so, parasitic noise related to engine running can affect the quality of knock measurement when using this method [19].

There are variety of ways in measuring knocking without experimenting on an engine to preserve the engine life. One of which is by large eddy simulation (LES) [20 - 21] which can be very helpful to cut down cost of full scale testing. Another simulation method is done by a parametric modelling approach where vibration signal of the cylinder block is modelled by auto regressive moving average (ARMA) parametric model [23]. Other simulation that use equations to study the effects of knocking can be seen in this research [24] in which a pressure wave equation of ICE is derived and modelled and then coupled 
with KIVA-3V codes with reduced kinetics mechanism. The oscillation pressure induced by auto-ignition was accurately simulated using the model. One other technique of determining knocking is by using the prediction method where using a model to mimic the combustion chamber by means of two zones, which are one in front and one behind the flame front. It is performed by conjuring up a theoretical model using equations to imitate the combustion of SI engines [22]. Although there are many methods in measuring knock either through simulation or prediction, theoretical studies no matter how accurate, cannot hold up with the actual test as a lot of deciding factors can affect the results. Hence, the scope of this research will only focus on the vibration at one point which could be consider the engine relative knock index detected by a knock sensor accelerometer.

Concerning this research, there are some examples of other studies that has been conducted similar type of testing approach. One relatable research [25] that can be found done in Malaysia was a study on part-load performance and emission of a SI engine fuelled with RON95 and RON97 gasoline. It was conducted due to the rapid rise and fall of the country fuel prices and determining whether using gasoline of a higher octane is beneficial in terms of economy. Another study [26] which was also similar, researched on the effects of RON and fuel system on SI engine performance and emissions by using Saudi Arabian RON91 and RON95 fuel with port injection and direct injection system. They also worked on the effects of varying spark timing on the performance and emission characteristics using the same mentioned fuel RONs [27]. Other studies that tried to examine between two fuel grades (RON90 \& RON95) was performed Ali Alahmer and Wail Aladayleh [28], where they found using octane grades higher than requirement will decreased the engine performance but will have lower NOx and CO emission concentration for the higher RON. They also found that using a higher octane can incur higher noise. There was also an investigation [29] carried out on finding the effects of varying spark timing at different octane ratings on engine performance and emission characteristics where the research tested five different types of RON (91, 93, 95, 97 and 98). Hence, this paper will study upon various fuel from different gasolines manufacturers with the same octane number to determine whether or not all are different or the same without altering any other variables such as engine tuning or using other fuel RON.

\section{Methodology}

In this research, three different brands of fuel, Brand A (A95), Brand B (B95), and Brand C (C95) were tested. All of the mentioned brands were categorized in the same octane rating of RON95. The process of testing the fuels performance was done using Land \& Sea's DYNOmite Engine Dynamometer (Fig. 1). Engine testing parameters conducted were only to focus on performance of the engine where data collected from each run were power (hp) and torque $(\mathrm{Nm})$ which determines engine performance of each tested gasoline brands. To determine the contributing factor towards performance figures, engine knocking data was also gathered by the knock sensor which was placed at the side of the engine block as can be seen in Fig. 2. This positions the knock sensor axis perpendicular to the thrust side of the piston skirt where the knocking signals are typically most useable near to the cylinder walls. The aforementioned location provides a strong "rattle" as detonation slams the piston's skirts against its bore. Ideal placement of the sensor can be vary by engine design, hence the mounting point of the knock sensor was determined by its original factory standard location and it is considered as the relative knock index (\%) at that attached position. 


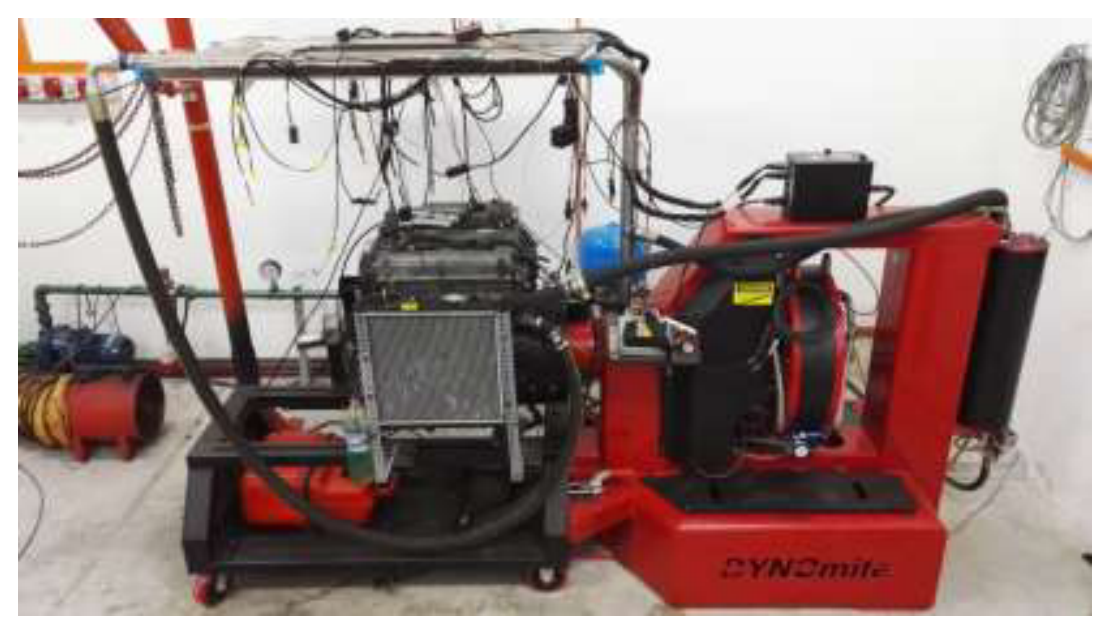

Fig. 1. Land \& Sea's DYNOmite engine dynamometer.

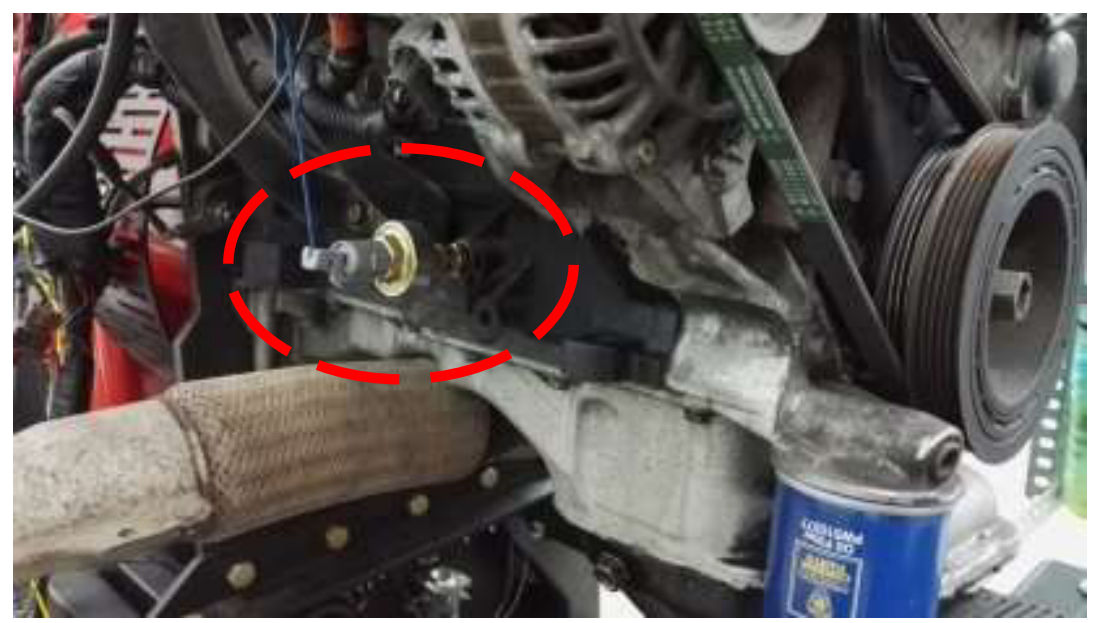

Fig. 2. Knock sensor position at the side of the engine block.

To conduct the experiment, certain procedures were needed to be in checked. The fuel tank was first drained using a fuel pump to completely remove the previous fuel that was used for testing and the test fuels were also filled by using the same pump to avoid any spillage. Before the test run for actual data collection, the fuel must run at least 15 minutes to ensure the engine is circulating only the test fuel to avoid any unnecessary data errors. The engine temperature before initiating the run must at least be at a minimum of $70^{\circ} \mathrm{C}$ and must not exceed $100^{\circ} \mathrm{C}$ while the test is carried out to ensure the optimum working temperature of the engine. The absorber temperature in the other hand must not exceed $60^{\circ} \mathrm{C}$ to prevent it from overheating. Five runs were recorded using automated sweep test where the engine speed starts from 2000 RPM and ends at 6000 RPM with increment of 100 RPM every second at wide open throttle. All data collected were stored using the engine dynamometer data acquisition electronics.

\section{Results and discussion}

From the graphs shown, it can generally be seen that all three fuel brands indeed have differences between one another in terms of engine performance. From Fig. 3, engine 
power when tested with gasolines of different brands, fuel A95 shown to be the best among the three with the highest power output of $79.58 \mathrm{hp}$ at $5400 \mathrm{rpm}$. At that particular engine speed also, both fuel B95 and C95 have nearly the same high power yield with $78.10 \mathrm{hp}$ and $78.17 \mathrm{hp}$ respectively. However from Fig. 4, at engine speed of range between 4500 rpm to $5000 \mathrm{rpm}$, the differences between the three fuels can be seen clearly. A95 have a better overall power output at that range while B95 is the lowest. There is also need to mention that all tested brands have the same trend of descending power yield when referred to the graph where the rate of power decrease for fuels A95, B95, and C95 are $-1.076 \mathrm{hp} / \mathrm{s}$, $-1.074 \mathrm{hp} / \mathrm{s}$ and $-1.118 \mathrm{hp} / \mathrm{s}$ respectively.

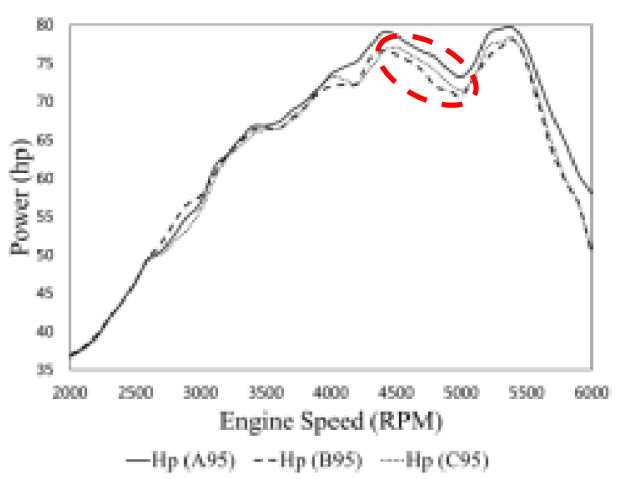

Fig. 3. Power vs. Engine Speed of RON95 fuel brands.

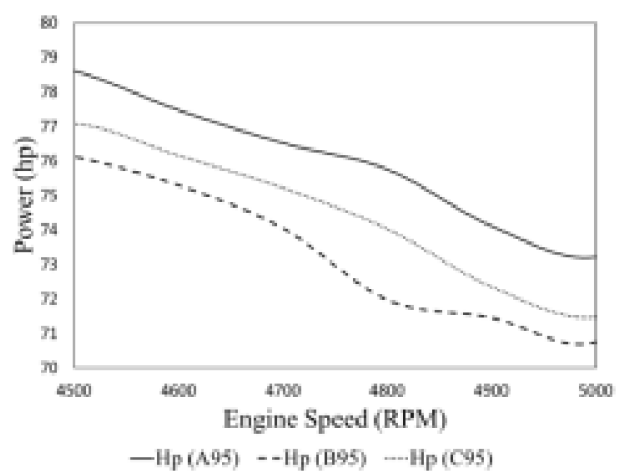

Fig. 4. Enlarged view of engine power at 4500 -5000 rpm range.

In Fig. 5, results show that A95 and B95 almost have the same highest magnitude value of torque with $140.4 \mathrm{Nm}$ and $139.8 \mathrm{Nm}$ both at $3300 \mathrm{rpm}$. C95 is slightly lower than the former mentioned with $138.7 \mathrm{Nm}$ at $3200 \mathrm{rpm}$. Closer examination with referred to Fig. 6 , at speed range of engine from $4500 \mathrm{rpm}$ to $5000 \mathrm{rpm}$, the differences between gasoline RONs can be clearly analyzed. In that specific range, fuel A95 again have a better overall torque figures compare to both B95 and C95. The trend of the torque output between the three brands is also the same with decreasing torque yield across the mentioned range. This is further supported by the rate of decrease of torque between A95, B95, and C95 where the results are $-4.04 \mathrm{Nm} / \mathrm{s},-3.94 \mathrm{Nm} / \mathrm{s}$, and $-4.08 \mathrm{Nm} / \mathrm{s}$ respectively.

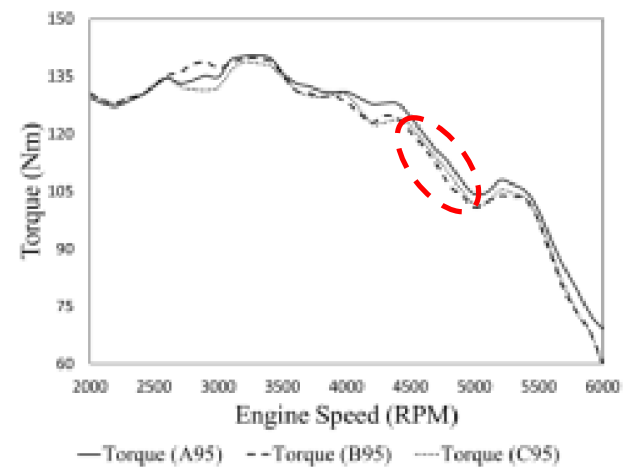

Fig. 5. Torque vs. Engine Speed of RON95 fuel brands.

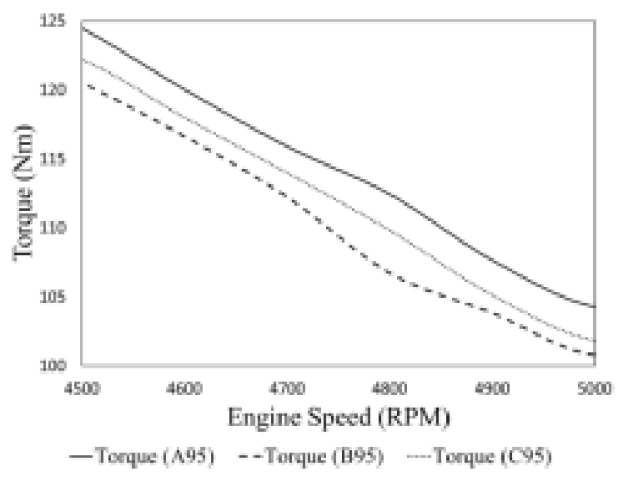

Fig. 6. Enlarged view of engine torque at 4500 $-5000 \mathrm{rpm}$ range.

Based on the performance figures mentioned, it needs to be stated that when the power and torque output is high, the relative knock index is reversely proportionate to it. This is evident from Fig. 8, where when A95 has the highest overall power and torque output at 
engine speed range from $4500 \mathrm{rpm}$ to $5000 \mathrm{rpm}$, the relative knock index of A95 is lower overall across that engine speed scope. Furthermore, at the same speed range of engine, the lowest performance output among the three which is B95 has the highest overall knocking effect while fuel C95 remains constant in the middle from performance figures to relative knock index. Therefore, what can be said from this analysis is that the knocking effect or relative knock index in this case, does indeed contribute to the overall engine performance.

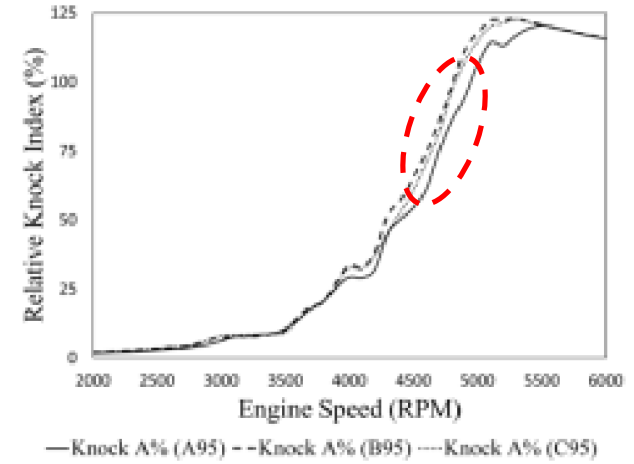

Fig. 7. Relative Knock Index vs. Engine Speed of RON95 fuel brands.

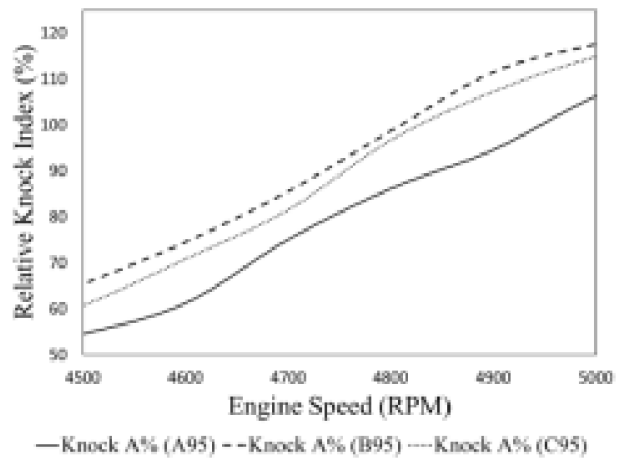

Fig. 8. Enlarged view of relative knock index at $4500-5000 \mathrm{rpm}$ range.

Nevertheless, one important issue that needs to be address in this matter is whether or not the differences between the gasoline producers of the same RON is significant or marginal. To do this, fuel C95 is set as the baseline to compare it between the other two fuel brands. From Fig. 4, fuel A95 only have at most the highest power increase of only $2.3 \%$, while fuel B95 at most decrease by $2.7 \%$. For torque difference, fuel A95 only have a maximum increase of only $2.4 \%$, while B95 decreases to only at a maximum of $2.7 \%$ which can be seen in Fig. 6. However, for relative knock index with referred to Fig. 8, fuel A95 performed relatively better when compared to the baseline with a maximum decrease to $11.7 \%$, while B95 only increase at most by $4 \%$.

\section{Conclusions}

From all the results gathered, it can be concluded that all tested gasoline brands of the same octane rating does indeed effect the overall performance of the engine but only by a small gap. Moreover, with the power and torque output having a difference of less than $3 \%$, it shows that the fuel manufacturers really follows the guidelines in maintaining the quality of the fuel to a certain octane rating. In addition to that, it can be put to rest of the debate of which brands is better when comparing to one and another as proved from the results that all fuel brands when tested for engine performance gives an output of relatively similar. Hence, the general public would not need to only focus a certain fuel brand to use as all are in the same octane rating and performs roughly the same. From this paper on, further studies would be conducted to determine if the emissions would have a similar effect as well when tested with the same experimental procedures.

The authors would like to give formal recognition to Universiti Teknikal Malaysia Melaka (UTeM) for providing laboratory facilities to conduct the engine testing experiment for this research. Further credit is given towards UTeM for supporting this study financially under the RAGS grant with project code RAGS/1/2014/TK06/FKM/B00071. 


\section{References}

1. N. Nikolaou, C.E. Papadopoulos, I.A. Gaglias, and K.G. Pitarakis. "A new non-linear calculation method of isomerisation gasoline research octane number based on gas chromatographic data." Fuel 83.4-5 (2004).

2. L. Guan, X.L. Feng, Z.C. Li, and G.M. Lin. "Determination of octane numbers for clean gasoline using dielectric spectroscopy." Fuel 88.8 (2009).

3. N. Rankovic, G. Bourhis, M. Loos, and R. Dauphin. "Understanding octane number evolution for enabling alternative low RON refinery streams and octane boosters as transportation fuels." Fuel 150 (2015).

4. C. Sayin, I. Kilicaslan, M. Canakci, and N. Ozsezen. "An experimental study of the effect of octane number higher than engine requirement on the engine performance and emissions." Applied Thermal Engineering 25.8-9 (2005).

5. S. S.Kish, A. Rashidi, H. R. Aghabozorg, and L. Moradi. "Increasing the octane number of gasoline using functionalized carbon nanotubes." Applied Surface Science 256.11 (2010).

6. H. Wei, D. Feng, M. Pan, J. Pan, X. Rao, and D. Gao. "Experimental investigation on the knocking combustion characteristics of n-butanol gasoline blends in a DISI engine." Applied Energy 175 (2016).

7. D. A. Rothamer, and J. H. Jennings. "Study of the knocking propensity of 2,5dimethylfuran-gasoline and ethanol-gasoline blends." Fuel 98 (2012).

8. T. Cerri, G. D'Errico, and A. Onorati. "Experimental investigations on high octane number gasoline formulations for internal combustion engines." Fuel 111 (2013).

9. C. Rahmouni, G. Brecq, M. Tazerout, and O. Le Corre. "Knock rating of gaseous fuels in a single cylinder spark ignition engine." Fuel 83.3 (2004).

10. C. Hudson, X. Gao, and R. Stone. "Knock measurement for fuel evaluation in spark ignition engines." Fuel 80.3 (2001).

11. S. Szwaja, K. Bhandary, and J. Naber. "Comparisons of hydrogen and gasoline combustion knock in a spark ignition engine." International Journal of Hydrogen Energy 32.18 (2007).

12. A. D. Gaeta, V. Giglio, G. Police, and N. Rispoli. "Modeling of in-cylinder pressure oscillations under knocking conditions: A general approach based on the damped wave equation." Fuel 104 (2013).

13. E. Galloni. "Dynamic knock detection and quantification in a spark ignition engine by means of a pressure based method." Energy Conversion and Management 64 (2012).

14. J. Rudloff, J.-M. Zaccardi, S. Richard, and J.m. Anderlohr. "Analysis of pre-ignition in highly charged SI engines: Emphasis on the auto-ignition mode." Proceedings of the Combustion Institute 34.2 (2013).

15. G. Shu, J. Pan, and H. Wei. "Analysis of onset and severity of knock in SI engine based on in-cylinder pressure oscillations." Applied Thermal Engineering 51.1-2 (2013).

16. N. Kawahara, E. Tomita, and Y. Sakata. "Auto-ignited kernels during knocking combustion in a spark-ignition engine." Proceedings of the Combustion Institute 31.2 (2007).

17. S. S. Merola, and B. M. Vaglieco. "Knock investigation by flame and radical species detection in spark ignition engine for different fuels." Energy Conversion and Management 48.11 (2007).

18. X. Zhen, Y. Wang, S. Xu, Y. Zhu, C. Tao, T. Xu, and M. Song. "The engine knock analysis - An overview." Applied Energy 92 (2012).

19. G. Brecq, J. Bellettre, and M. Tazerout. "A new indicator for knock detection in gas SI engines." International Journal of Thermal Sciences 42.5 (2003). 
20. A. Robert, S. Richard, O. Colin, L. Martinez, and L. De Francqueville. "LES prediction and analysis of knocking combustion in a spark ignition engine." Proceedings of the Combustion Institute 35.3 (2015).

21. G. Lecocq, S. Richard, J. B. Michel, and L. Vervisch. "A new LES model coupling flame surface density and tabulated kinetics approaches to investigate knock and preignition in piston engines." Proceedings of the Combustion Institute 33.2 (2011).

22. E. Moses, A. L. Yarin, and P. B. Yoseph. "On Knocking Prediction in Spark Ignition Engines." Combustion and Flame 101.3 (1995).

23. M. M. Ettefagh, M. H. Sadeghi, V. Pirouzpanah, and H. Arjmandi Tash. "Knock detection in spark ignition engines by vibration analysis of cylinder block: A parametric modeling approach." Mechanical Systems and Signal Processing 22.6 (2008).

24. J. Pan, G. Shu, and H.Wei. "Research on in-cylinder pressure oscillation characteristic during knocking combustion in spark-ignition engine." Fuel 120 (2014).

25. T. I. Mohamad, and H. G. How. "Part-load performance and emissions of a spark ignition engine fueled with RON95 and RON97 gasoline: Technical viewpoint on Malaysia's fuel price debate." Energy Conversion and Management 88 (2014).

26. S. Binjuwair, T. I. Mohamad, A. Almaleki, A. Alkudsi, and I. Alshunaifi. "The effects of research octane number and fuel systems on the performance and emissions of a spark ignition engine: A study on Saudi Arabian RON91 and RON95 with port injection and direct injection systems." Fuel 158 (2015).

27. S. Binjuwair, and A. Alkudsi. "The effects of varying spark timing on the performance and emission characteristics of a gasoline engine: A study on Saudi Arabian RON91 and RON95." Fuel 180 (2016).

28. A. Alahmer, and W. Aladayleh. "Effect two grades of octane numbers on the performance, exhaust and acoustic emissions of spark ignition engine." Fuel 180 (2016).

29. C. Sayin. "The impact of varying spark timing at different octane numbers on the performance and emission characteristics in a gasoline engine." Fuel 97 (2012). 